\title{
Avaliação de conteúdos relacionados à cárie dentária em livros didáticos em escolas públicas do ensino fundamental de Vitória-ES
}

\author{
Evaluation of content related to dental caries in teaching books in public schools of elementary \\ education in Vitória-ES \\ Evaluación de contenidos relacionados con caries dental en libros didácticos de escuelas públicas de \\ educación primaria de Vitória-ES
}

Recebido: 21/09/2021 | Revisado: 30/09/2021 | Aceito: 04/10/2021 | Publicado: 07/10/2021

\author{
Jordana Rodrigues da Cruz \\ ORCID: https://orcid.org/0000-0002-0890-9783 \\ Universidade Federal do Espírito Santo, Brasil \\ E-mail: jordanarodriguesjr@hotmail.com \\ Gabriele Amorim Cordeiro \\ ORCID: https://orcid.org/0000-0003-0042-4009 \\ Universidade Federal do Espírito Santo, Brasil \\ E-mail: gabi.amorimcordeiro@ hotmail.com \\ Manoelito Ferreira Silva-Junior \\ ORCID: https://orcid.org/0000-0001-8837-5912 \\ Universidade Estadual de Ponta Grossa, Brasil \\ E-mail: manoelito_fsjunior@hotmail.com \\ Luiz Gustavo Dias Daroz \\ ORCID: https://orcid.org/0000-0002-4925-7443 \\ Universidade Federal do Espírito Santo, Brasil \\ E-mail: lgdaroz@msn.com \\ Cláudia Batitucci dos Santos Daroz \\ ORCID: https://orcid.org/0000-0001-6810-2810 \\ Universidade Federal do Espírito Santo, Brasil \\ E-mail: claudiabatitucci@yahoo.com.br
}

\begin{abstract}
Resumo
O objetivo deste estudo foi avaliar a presença de conteúdos relacionados à cárie dentária em livros didáticos de escolas públicas do ensino fundamental I ( $1^{\circ}$ ao $5^{\circ}$ ano $)$ e II $\left(6^{\circ}\right.$ ao $9^{\circ}$ ano). O estudo, do tipo documental descritivo com abordagem quantitativa, utilizou uma ficha padronizada e desenvolvida para avaliar o conteúdo dos livros-texto de primeira escolha de Ciências em 30 escolas da cidade de Vitória-ES, Brasil. Foram disponibilizados 130 livros, 10 para cada ano do Ensino Fundamental I e 20 para cada ano de Ensino Fundamental II. Após remover as duplicatas, 29 títulos foram analisados. Um total de 11 livros $(37,9 \%)$ abordavam o conteúdo cárie dentária, disponíveis apenas para os $1^{\circ}(n=1), 2^{\circ}(n=2), 4^{\circ}(n=1), 5^{\circ}(n=3)$ e $8^{\circ}(n=4)$ anos escolares. Dos livros que abordam o tema cárie dentária, os conteúdos mais abordados foram o papel das bactérias no aparecimento da cárie $(81,8 \%)$ e o estímulo as práticas de higiene $(72,7 \%)$; e os menos frequentes foram o papel do flúor na prevenção da cárie (18,2\%) e o aspecto do tratamento restaurador da cárie $(18,2 \%)$. Houve maior diversificação de conteúdo nos livros do $2^{\circ}$ ano $(66,7 \%)$ e do $8^{\circ}$ ano $(100,0 \%)$ dos 6 conteúdos avaliados. De modo geral, os conteúdos eram mais completos nos livros do $8^{\circ}$ ano. Conclui-se que o tema cárie dentária é abordado em menos da metade dos livros-texto de ciências, sendo mais presente no ensino fundamental I e mais completo no ensino fundamental II.
\end{abstract}

Palavras-chave: Cárie dentária; Educação em saúde; Conhecimento; Educação.

\begin{abstract}
The aim of this study was to evaluate the presence of contents related to dental caries in textbooks of public elementary schools I (1st to 5th grade) and II (6th to 9th grade). The descriptive documentary study with a quantitative approach used a standardized form developed for the study to evaluate the content of the textbooks of first choice of Sciences in 30 schools in the city of Vitória-ES, Brazil. 130 books were made available, 10 for each year of Elementary School I and 20 for each year of Elementary School II. After removing the duplicates, 29 titles were analyzed. A total of 11 books (37.9\%) addressed the content of dental caries, and are available only for the 1 st (n $=1)$, 2nd $(n=2)$, 4th $(n=1)$, 5th $(n=3)$ and 8th $(n=4)$ school years. Of the books that deal with dental caries content, the most discussed content in the books were the role of bacteria in the appearance of caries $(81.8 \%)$ and
\end{abstract}


encouraging hygiene practices $(72.7 \%)$, and the least frequent was the role fluoride in the prevention of caries (18.2\%) and the aspect of restorative caries treatment (18.2\%). There was greater diversification of content in books from 2 years $(66.7 \%)$ and 8 years $(100.0 \%)$ of the 6 contents evaluated. And in general the contents were more complete in the books of the 8th year. It is concluded that the theme of dental caries is addressed in less than half of the science textbooks, more present in elementary school I and more complete in elementary school II.

Keywords: Dental caries; Health education; Knowledge; Education.

\section{Resumen}

El objetivo de este estudio fue evaluar la presencia de contenidos relacionados con la caries dental en los libros de texto de las escuelas primarias públicas I $\left(1^{\circ}\right.$ a $5^{\circ}$ grado $)$ y II $\left(6^{\circ}\right.$ a $9^{\circ}$ grado $)$. El estudio descriptivo tipo documento con enfoque cuantitativo utilizó un formulario estandarizado desarrollado para el estudio para evaluar el contenido de libros de texto de ciencias de primera elección en 30 escuelas de la ciudad de Vitória-ES, Brasil. Se pusieron a disposición 130 libros, 10 por cada año de la Escuela Primaria I y 20 por cada año de la Escuela Primaria II. Después de eliminar los duplicados, se analizaron 29 títulos. Un total de 11 libros (37,9\%) abordaron el contenido de caries dental, y solo están disponibles para el $10(n=1), 20(n=2), 4 o(n=1), 5 o(n=3)$ y 8o. $(n=4)$ años escolares. De los libros que abordan el contenido de la caries dental, los contenidos más discutidos en los libros fueron el papel de las bacterias en la aparición de caries $(81,8 \%)$ y el fomento de las prácticas de higiene $(72,7 \%)$, y el menos frecuente fue el papel de fluoruro en la prevención de la caries $(18,2 \%)$ y el aspecto del tratamiento reparador de la caries $(18,2 \%)$. Hubo mayor diversificación de contenidos en los libros de $2^{\circ}$ año $(66,7 \%)$ y $8^{\circ}$ año $(100,0 \%)$ de los 6 contenidos evaluados. Y en general los contenidos fueron más completos en los libros de octavo grado. Se concluye que el tema de la caries dental se aborda en menos de la mitad de los libros de texto de ciencias, más presente en la Primaria I y más completo en la Primaria II.

Palabras clave: Caries dental; Educación en salud; Conocimiento; Educacion.

\section{Introdução}

A cárie dentária é uma doença açúcar-biofilme dependente, na qual o metabolismo das bactérias presentes no biofilme dental gera alterações no pH, levando à perda de material inorgânico da estrutura dentária (Fejerskov, 2004). A doença cárie é multifatorial e complexa, determinada por fatores como: composição do biofilme, frequência e composição da dieta alimentar, e modulada pela composição salivar, quantidade e velocidade fluxo salivar, hábitos de higiene, presença de fluoretos, condições de acesso aos serviços de saúde e socioeconômicas, dentre outros. Estes fatores, isolados, não são capazes de iniciar a lesão de cárie, mas interferem na sua progressão (Leites et al., 2005).

$\mathrm{O}$ alto consumo de alimentos industrializados, com grande teor de carboidratos e higiene bucal insatisfatória entre crianças e adolescentes torna-os grupos de risco para o surgimento e progressão de lesões cariosas (Braga \& Leite, 2010). No entanto, os indivíduos em fase pré-escolar e escolar ficam suscetíveis a intervenções que proporcionem saúde e propícias à introdução de hábitos saudáveis, como também devem ser direcionadas aos responsáveis pelas crianças e adolescentes (Rodrigues, 2008).

A Organização Mundial da Saúde reconhece a intersetorialidade entre o campo da saúde e educação como primordial na contribuição educativa que impacta positivamente na saúde (Aquilante, 2003). A escola possui função indispensável na aquisição de conhecimento, hábitos e atitudes relacionados à prevenção de doenças e promoção de saúde, e deve ser um ambiente de ligação com a família e sociedade (Rodrigues, 2008). Nesse contexto, os educadores e educandos passam do campo teórico para executores da sua própria saúde, e, por esse motivo, o cirurgião-dentista deve ser de forma integrada e interdisciplinar, buscando promover a educação em saúde (Martins et al., 2008).

Apesar de ser próspera a atuação dos professores na implementação de conhecimento e hábitos saudáveis em saúde, inclusive em saúde bucal, é necessário que os docentes possuam acesso a fontes seguras e adequadas de informações. Sendo assim, os materiais didáticos, por meio dos livros-texto fornecidos pelas escolas, tornam-se fundamentais nesse processo. Com o intuito de identificar a presença do conteúdo de cárie dentária e a qualidade das informações sobre o processo saúde-doença bucal e o aprofundamento das informações transmitidas com o avançar dos anos escolares, o objetivo deste estudo foi avaliar a presença de conteúdos relacionados à cárie dentária em livros didáticos de escolas públicas do ensino fundamental $\mathrm{I}\left(1^{\circ}\right.$ ao $5^{\circ}$ 
ano) e II ( $6^{\circ}$ ao $9^{\circ}$ ano).

\section{Metodologia}

O presente estudo, do tipo documental e descritivo com abordagem quantitativa (Estrela, 2018; Pereira et al., 2018), foi submetido e aprovado no Comitê de Ética em Pesquisa da Universidade Federal do Espírito Santo sob número 3.062.985.

Após concessão da autorização pela Secretaria Municipal de Educação (SEME) do município de Vitória-ES, Brasil, um total de 30 escolas (35\%) da rede pública de ensino municipal e estadual foram selecionadas aleatoriamente por conveniência, de acordo com a localização geográfica e facilidade de acesso para a realização da pesquisa; sendo 10 escolas de ensino fundamental I, que compreende do $1^{\circ}$ ao $5^{\circ}$ ano, e 20 escolas do ensino fundamental II, que engloba do $6^{\circ}$ ao $9^{\circ}$ ano.

O contato com as escolas foi feito inicialmente por telefone e posteriormente de forma presencial, quando foi feita a descrição do projeto de pesquisa e sua importância, apresentando-se a concessão de autorização conferida pela SEME. Somente após a entrega do termo de confidencialidade e sigilo e coleta da assinatura da anuência, pelo gestor responsável de cada instituição de ensino, era realizada a coleta de dados. Em seguida, os livros foram identificados, com o auxílio dos funcionários das bibliotecas, que apresentaram os livros disponíveis conforme a grade curricular de cada ano. Foram avaliados os livros de primeira escolha da grade curricular de cada ano, adotados em sala de aula e disponíveis nas bibliotecas das escolas, com o uso de um instrumento padronizado e desenvolvido para este estudo, para averiguar a presença e classificar o conteúdo de cárie dentária abordado em livros de Ciências do $1^{\circ}$ ao $9^{\circ}$ ano do ensino público fundamental.

A coleta das informações no material foi realizada em cada escola em 2019 por duas pesquisadoras, por meio de uma ficha de avaliação padronizada e desenvolvida para o estudo, contendo informações sobre os livros, como título, autor, edição, editora e dados que respondessem aos questionários quanto à presença do conteúdo cárie dentária, suas formas de prevenção e tratamento presentes nos livros-texto.

Após a coleta de dados, eles foram analisados descritivamente e quantitativamente, em frequências absolutas (n) e relativas (\%). Vale ressaltar que, para a descrição dos dados, foram mantidos a privacidade e o sigilo de cada instituição participante.

\section{Resultados}

Nas 30 escolas da rede pública de ensino fundamental, foram acessados 130 livros, que correspondem à análise de 29 títulos da área de Ciências do $1^{\circ}$ ao $9^{\circ}$ ano (Tabela 1). No ensino fundamental I, foram acessados 50 livros, sendo 10 livros por ano escolar, e no ensino fundamental II, foram analisados 80 livros, sendo 20 livros por ano escolar, o que conferiu um total de 13 e 16 títulos analisados, respectivamente, para cada tipo de ensino.

Dos 29 títulos encontrados, o conteúdo cárie dentária foi encontrado em 37,9\% dos livros, apresentando-se em todos os livros do $2^{\circ}, 5^{\circ}$ e $8^{\circ}(100,0 \%)$ ano escolar (Tabela 1$)$. 
Tabela 1. Frequências de livros encontrados/editoras, títulos analisados e presença do conteúdo cárie dentária. Vitória-ES, Brasil, 2019.

\begin{tabular}{lcc}
\hline Ano Escolar & Títulos analisados (n) & $\begin{array}{c}\text { Com Tema Cárie } \\
\mathrm{n}(\%)\end{array}$ \\
\hline $1^{\mathbf{o}}$ ano & 3 & $1(33,3)$ \\
$2^{\mathrm{o}}$ ano & 3 & $3(100,0)$ \\
$3^{\mathrm{o}}$ ano & 3 & $0(0,0)$ \\
$4^{\mathbf{o}}$ ano & 2 & $1(50,0)$ \\
$5^{\mathrm{o}}$ ano & 2 & $2(100,0)$ \\
$6^{\mathrm{o}}$ ano & 4 & $0(0,0)$ \\
$7^{\mathbf{o}}$ ano & 4 & $0(0,0)$ \\
$8^{\mathbf{o}}$ ano & 4 & $4(100.0)$ \\
$9^{\circ}$ ano & 4 & $0(0,0)$ \\
\hline Total & 29 & $11(37,9)$ \\
\hline
\end{tabular}

Fonte: Dados da pesquisa.

Dos livros que abordam o conteúdo cárie dentária $(n=11)$, os conteúdos mais abordados foram: o papel das bactérias no aparecimento da cárie $(81,8 \%$ ) (etiologia) e o estímulo as práticas de higiene bucal (72,7\%), como a escovação dos dentes com pasta e uso de fio dental. Os conteúdos menos frequentes foram o papel do flúor na prevenção da cárie (18,2\%) e o aspecto do tratamento restaurador $(18,2 \%)$ (Tabela 2$)$.

Observou-se que, para as crianças mais novas, ainda no Ensino Fundamental I, as informações são passadas de forma mais lúdica e colorida, com histórias, desenhos, contos, figuras e quadrinhos do que é feito para os alunos do Ensino Fundamental II, de modo que as crianças possam compreender bem.

Houve maior diversificação de conteúdo nos livros do $2^{\circ}(66,7 \%)$ e do $8^{\circ}$ ano $(100 \%)$ dos 6 conteúdos avaliados, sendo que os conteúdos eram mais completos nos livros do $8^{\circ}$ ano (Tabela 2 ).

Tabela 2. Frequência do conteúdo de cárie dentária abordado nos livros didáticos na rede de ensino fundamental público. Vitória-ES, Brasil, 2019.

\begin{tabular}{|c|c|c|c|c|c|c|c|c|c|c|}
\hline \multirow{3}{*}{ O conteúdo de cárie dentária contemplava } & \multicolumn{10}{|c|}{ Ano Curricular } \\
\hline & \multicolumn{2}{|c|}{$\begin{array}{c}1 \\
(n=1)\end{array}$} & \multicolumn{2}{|c|}{$\begin{array}{c}2 \\
(\mathrm{n}=3)\end{array}$} & \multicolumn{2}{|c|}{$\begin{array}{c}4 \\
(n=1)\end{array}$} & \multicolumn{2}{|c|}{$\begin{array}{c}5 \\
(n=2)\end{array}$} & \multicolumn{2}{|c|}{$\begin{array}{c}8 \\
(n=4)\end{array}$} \\
\hline & $\mathrm{S}$ & $\mathrm{P}$ & $\mathrm{S}$ & $\mathrm{P}$ & $\mathrm{S}$ & $\mathrm{P}$ & $\mathrm{S}$ & $\mathrm{P}$ & $\mathrm{S}$ & $\mathrm{P}$ \\
\hline Papel das bactérias no aparecimento da cárie & - & - & - & 3 & 1 & - & 2 & - & 3 & - \\
\hline Papel do consumo do açúcar no aparecimento da cárie & - & - & 1 & 2 & - & 1 & - & - & 3 & - \\
\hline Estímulo às práticas de higiene bucal & 1 & - & 3 & - & - & 1 & - & - & 3 & - \\
\hline Papel do flúor na prevenção de cárie & - & - & - & - & - & - & - & - & 2 & - \\
\hline Papel das visitas ao dentista na prevenção da cárie & - & - & - & 2 & - & - & - & - & 4 & - \\
\hline Aspecto do tratamento restaurador da cárie & - & - & - & - & - & - & - & - & 1 & 1 \\
\hline
\end{tabular}

S: Sim. P: Sim, Parcialmente.

Fonte: dados da pesquisa.

\section{Discussão}

Os docentes possuem conhecimentos técnicos e um relacionamento com os discentes que geram influências favoráveis junto aos alunos, com a finalidade de desenvolver bons hábitos em saúde, ao passo que a atuação dos educadores concebe um importante mecanismo para o alcance de índices de saúde favoráveis na população, principalmente decorrente de uma relação diária e prolongada (Rodrigues, 2008).

Estudos anteriores mostraram conhecimento adequado sobre cárie dentária, mas não abordado pelos professores, seja na educação pré-escolar (Aragão et al., 2010) ou no ensino médio (Cordeiro et al., 2019). Ainda, que o conhecimento não foi 
adquirido durante a graduação, mas adveio de cirurgiões-dentistas (Antunes et al., 2006; Cordeiro et al., 2019), por isso, saber sobre o conteúdo presente no material didático disponível, torna-se necessário. No entanto, neste estudo, o conteúdo cárie dentária se mostra presente em pouco mais de um terço dos títulos avaliados, e foi identificada padronização nos livros-texto indicados para as turmas no município.

O que rege o ensino nas escolas de todo país se encontra estabelecido nas Diretrizes Curriculares Nacionais, disponível pelo Ministério da Educação, em que assuntos relacionados à área da saúde sejam abordados nas Disciplinas de Ciências Humanas, no entanto, esse tema não é obrigatório dentro dos conteúdos do Ensino Fundamental. Em um estudo de Tanaka et al. (2008) sobre conhecimentos em saúde bucal, foi observado que os pontos abordados no ensino fundamental são apenas conteúdos relacionados à escovação dentária e substituição de dentes, os quais não são suficientes para uma compreensão da doença cárie, sua etiologia e formas de prevenção/tratamento.

O que se verificou, no presente estudo, foi a abordagem do assunto de forma desconexa e fragmentada. Além disso, não houve padronização no ano ou anos escolares mais adequados para a inclusão do tema no Ensino Fundamental I, mas aconteceu para o Ensino Fundamental II, inclusive com uma maior diversificação de conteúdos sobre a temática e seu aprofundamento. Nesse sentido, apesar de o Ministério da Saúde apresentar o ambiente escolar com atribuição pedagógica, bem como social e política, com o intuito de transformar os indivíduos, o presente estudo mostrou que a escola pode não estar exercendo o seu potencial papel social como deveria. A idade escolar constitui o período mais adequado para o ensino de conhecimentos em saúde e, assim, se promover o incentivo da construção de novos hábitos, pois, com o avançar da idade, torna-se cada vez mais difícil a introdução de hábitos e mudanças em sua rotina (Weyne \& Harari, 2002).

Os livros didáticos são ferramentas fundamentais para o processo de aprendizagem, e, ao serem utilizados durante todo percurso de formação acadêmica, possuem grande influência sobre a ministração dos conhecimentos necessários. Por tal motivo, as informações neles contidas devem estar corretas e expostas de forma que o ensino seja facilitado e satisfatório. As informações contidas nos livros didáticos sobre saúde bucal necessitam ser revisadas, pois, para que se tenha educação em saúde, é necessário conhecimento técnico e científico de forma correta, abrangendo maior número de alunos, principalmente os que estão inseridos nos anos escolares mais avançados, uma vez que as políticas de saúde e atividades escolares têm dado maior atenção às crianças, deixando os adolescentes, em sua maioria, descobertos (Leites et al., 2005).

Entre as temáticas abordadas, na maioria dos livros analisados o papel do biofilme dental para uma compreensão do processo saúde/doença cárie dentária foi um dos temas mais presentes, ao passo que o papel do consumo de açúcar no processo de formação da cárie dentária foi menos evidenciado. No entanto, ambos foram mais superficialmente abordados nos livros do Ensino Fundamental I, e mais adequadamente no 8 ano, ou seja, apenas em um ano do Ensino Fundamental II.

O biofilme dental, formado sobre a superfície dentária, é constituído por interações de diferentes microrganismos e seu metabolismo gera desequilíbrio no pH (Lima, 2007). Uma dieta rica em carboidratos, principalmente sacarose, é a energia que o metabolismo bacteriano precisa para produzir polissacarídeos extracelulares que favorecem a maturação e o aumento na espessura do biofilme e a produção de ácidos orgânicos. Fatores como a presença de íons supersaturados, a exemplo de cálcio e fosfato na saliva, e a capacidade tampão vão proteger os tecidos minerais, mas a ingestão frequente de dieta cariogênica gera um desequilíbrio nesse processo contínuo de des e remineralização dos tecidos da superfície dentária, para o surgimento e progressão da lesão de cárie (Lima, 2007) e para inflamação nos tecidos periodontais (Rigodanzo \& Unfer, 2008).

Outro fator muito importante no processo de des e remineralização é o flúor, sendo um dos conteúdos menos abordado nos livros didáticos analisados, e esteve presente em totalidade nos livros do $8^{\circ}$ ano escolar. O mecanismo de ação do flúor resulta em resistência do tecido mineral, seja de esmalte dentário e dentina, na presença de pH crítico do meio bucal. No entanto, o íon deve estar presente de forma contínua e prolongada, pela sua baixa substantividade, e considerando sua ação 
tópica ${ }^{14}$. Assim, a distribuição de rede de abastecimento de água fluoretada e a inclusão de fluoretos nos dentifrícios apresentaram uma redução considerável no índice de cárie na população (Maltz et al., 2016).

Nessa perspectiva, o uso contínuo do flúor, o consumo consciente dos carboidratos, principalmente de açúcares, e o controle do biofilme dental são métodos fundamentais para prevenção e limitação das principais doenças bucais, cárie dentária e doença periodontal (Narvai, 2000). O estímulo à prática de higiene bucal foi um dos conteúdos mais abordados nos livros analisados, e o conteúdo estava presente adequadamente. As práticas de higiene bucal, com a escovação dental e o uso do fio dental, são fundamentais para a desorganização do biofilme dental, e no caso de uso de dentifrício fluoretado, torna o flúor constante na cavidade buccal (Maltz et al., 2016; Narvai, 2000; Rigodanzo \& Unfer, 2008).

Além disso, o uso de fluoretos é um método largamente utilizado na prática odontológica, com o intuito de prevenção e tratamento da doença cárie. Sendo assim, a visita periódica ao cirurgião-dentista é um conteúdo importante para temática da cárie dentária, e também esteve presente na maioria dos livros didáticos. Apesar da ida frequente ao profissional ser fundamental para a manutenção da saúde bucal, o intervalo entre consultas não deve ser padronizado, pois depende da necessidade e do risco para as diversas patologias bucais, inclusive para cárie dentária. Nesse caso, o profissional vai analisar a exposição aos fatores de risco, como as práticas de higiene bucal, hábitos alimentares individuais, anatomia e posição dos dentes, aspectos socioeconômicos e culturais para determinar o risco de cárie e os intervalos adequados para essas consultas (Taglietta et al., 2011). Além disso, as visitas periódicas ao consultório permitem um acompanhamento constante para o diagnóstico de lesões iniciais, manutenção e acompanhamento de tratamentos executados, e para prevenir as doenças bucais através da educação em saúde de forma contínua (Hallberg \& Klingberg, 2007).

No caso de lesão de cárie com presença de cavidade, principalmente ativas, o tratamento restaurador é necessário. Esse conteúdo foi pouco abordado e esteve presente em sua totalidade nos livros do $8^{\circ}$ ano escolar. O diagnóstico da lesão de cárie é possível através do exame clínico profissional, ao se observar a superfície dentária limpa, seca e em condições ambientais adequadas. A possibilidade de diagnóstico a olho nu indica que o processo de desmineralização dentária se iniciou a um dado tempo e, não havendo intervenção a fim de se paralisar esse processo, haverá a sua continuidade, podendo levar à formação de uma cavidade na superfície do dente (Leites et al., 2005). Com a progressão do processo de desmineralização, há a possibilidade de episódios dolorosos, indicando que tal processo se estendeu até a próxima camada de formação dentária, a dentina. Quando há ocorrência de dor, indica que pode ter havido a formação de cavitações, assinalando que a perda mineral atingiu o seu estágio irreversível, sendo necessário intervenção profissional, de forma a substituir a estrutura dentária perdida (Rigodanzo \& Unfer, 2008).

No entanto, o tratamento restaurador, por si só, sem considerar os fatores causais e modificadores da cárie, pode se suceder a um alívio passageiro, visto que a cárie é uma doença multifatorial e complexa, podendo ser recorrente. Faz-se necessária a educação do indivíduo para torná-lo capaz de prevenir possíveis agravos à sua saúde, de forma a auxiliar o cuidado profissional, diminuindo o número de consultas necessárias, por se tornar um paciente de baixo risco (Leites et al., 2005).

O estudo apresenta limitações, como o fato de apenas avaliar o material didático livro-texto, ser realizado apenas em um município, ser realizado com material disponibilizado em escolas públicas, e não se ter ido em parte das escolas, o que pode ter reduzido o número de títulos encontrados, diminuindo-se, assim, a capacidade de avaliação de um número maior de livros/títulos. No entanto, o que se verificou foi padronização dos recursos didáticos utilizados e, assim, pode ter reduzido o impacto desses possíveis problemas. Além disso, a escolha por trabalhar com materiais da escola pública. Uma vez que a cárie apresenta distribuição desigual com polarização entre indivíduos com piores condições socioeconômicas, este assunto se torna ainda mais pertinente e necessário para os escolares do ensino público (Cruz et al., 2019). 


\section{Conclusão}

Um terço dos livros do ensino público fundamental contemplavam o conteúdo cárie dentária em sua estrutura. Pôde-se observar que, na maioria dos livros que abordava o conteúdo de cárie dentária, não ficou padronizado o ano de inclusão no Ensino Fundamental I, com inclusão em apenas um ano do Ensino Fundamental II, deixando, assim, os alunos de anos escolares mais avançados desprovidos de tais informações.

Não obstante os conteúdos do Ensino Fundamental I não apresentarem uma progressão de aprofundamento conforme o ano, essa perspectiva foi verificada no material didático do único ano do Ensino Fundamental II analisado. Os livros-texto abordavam o conteúdo de forma precisa e completa quanto à etiologia da cárie dentária e algumas formas de prevenção quando se tratava do estímulo e orientações sobre as práticas de higiene bucal, no entanto, se mostraram insuficientes quanto ao número de livros contemplados com tal variável.

As informações que expõem a importância do flúor e a possibilidade de tratamento restaurador da cárie são variáveis abordadas em pouquíssimos livros e limitadas apenas aos alunos do $8^{\circ}$ ano escolar. Desta forma, os autores sugerem a revisão e reformulação do conteúdo inserido nos livros didáticos, visto que eles se mostram insuficientes, na maioria dos casos, para a promoção do autocuidado.

Novos estudos, com um maior número de escolas - incluindo as particulares e as públicas de outros municípios, além das instituições de ensino estaduais - são recomendados para uma observação mais abrangente do tema cárie dentária nos livros didáticos do Ensino Fundamental I e II, de forma a melhor orientar os estudantes quanto ao autocuidado em saúde bucal.

\section{Referências}

Antunes, L. S., Antunes, L. A. A., Soraggi, M. B. S., Maia, L. C. \& Corvino, M. P. F. (2006). Auto-avaliação, conhecimento e práticas de professores e agentes de educação frente a saúde bucal. Braz. Oral Res., 20 (Supl.), 170.

Aquilante, A. G., Almeida, B. S.; Castro, R. F. M., Xavier, C. R. G., Peres, S. H. C. S. \& Bastos, J. R. M. (2003). A importância da educação em saúde pública para pré-escolares. Araçatuba-SP. Rev. Odontol. UNESP, 32, 39-45.

Aragão, A. K. R., Sousa, P. G. B., Ferreira, J. M. S., Duarte, R. C. \& Menezes, V. A. (2010). Conhecimento de professores das creches municipais de João Pessoa sobre saúde bucal infantil. Pesq. Bras. Odontoped. Clín. Integr., 10 (3), 393-398.

Braga, N. R. \& Leite, I. C. G. (2010). O cuidado com a saúde bucal do adolescente: orientações para os profissionais de saúde. Universidade Federal de Juiz de Fora; Juiz de Fora.

Cordeiro, G. A., Silva-Junior, M. F., Daroz, L. G. D. \& Santos-Daroz, C. B. (2019). Knowledge about dental caries among high school teachers. Rev ABENO, 19 (3), 133-143.

Cruz, R. K. S., Freitas, Y. N. L., Mendes, T. C. O., Silva, J. V., Machado, F. C. A., Rodrigues, M. P., et al. (2019). Spatial inequality of dental caries in the Brazilian territory. Braz. Oral Res., 33, e122.

Estrela, C. (2018). Metodologia Científica: Ciência, Ensino, Pesquisa. Editora Artes Médicas.

Fejerskov, O. (2004). Changing paradigms in concepts on dental caries: consequences for oral health care. Caries Res., 38 (3), $182-191$.

Hallberg, U. \& Klingberg, G. (2007). Giving low priority to oral healthcare. Voices from people with disabilities in a grounded theory study. Acta Odontol. Scand, 65 (5), 265-270.

Leites, A. C. B. R., Pinto, M. B., Souza, E. R. (2005). Aspectos microbiológicos da cárie dental. Salusvita, 25 (2), $239-252$.

Lima, J. E. O. (2007). Cárie dentária: um novo conceito. R. Dental Press Ortodon. Ortop. Facial, 6 (12), 119-130.

Maltz, M., Tenuta, L. M. A., Groisman, S. \& Cury, J. A. (2016). Cariologia: Conceitos básicos, diagnóstico e tratamento não restaurador. Artes Médicas.

Martins, V. R., Abrantes, F. N., Miasato, J. M. (2008). Professores como uma importante fonte de informação e promoção de saúde bucal. Pesq. Bras. Odontoped. Clín. Integr., 8 (1), 27-30.

Narvai, P. C. (2000). Cárie dentária e flúor: uma relação do século XX. Ciênc Saúde Colet., 2 (5), 381-392.

Pereira A. S. et al. (2018). Metodologia da pesquisa científicaUFSM.

Rigodanzo, L. \& Unfer, B. (2008). Análise dos livros didáticos do ensino fundamental e médio quanto aos conteúdos de saúde bucal. Educação (UFSM), 30 (1), 181-192. 
Research, Society and Development, v. 10, n. 13, e126101320849, 2021

(CC BY 4.0) | ISSN 2525-3409 | DOI: http://dx.doi.org/10.33448/rsd-v10i13.20849

Rodrigues, C. M. N. B. (2008). Comportamento, Hábitos e conhecimento de saúde oral das crianças: percepção dos pais/encarregados de educação. Universidade de Lisboa; Lisboa.

Taglietta, M. F. A., Bittar, T. O., Brandão, G. A. M., Vazquez, F. L., Paranhos, L. R. \& Pereira, A. C. (2011). Impacto de um programa de promoção de saúde escolar sobre a redução da prevalência da cárie em crianças pré-escolares de Piracicaba - SP. RFO, 16, 13-17.

Tanaka, C., Borgti, W. M. M., Moimaz, S. A. S., Saliba, N. A \& Garbin, C. A. S. (2008). Análise do conteúdo sobre saúde bucal no material didático da disciplina de ciências utilizado em escolas de ensino fundamental. Rev Odontol UNESP, 37 (2), 103-107.

Weyne, S. C. \& Harari, S. G. (2002). Cariologia: implicações e aplicações clínicas. In: Baratieri, L. N.; et al. Odontologia restauradora: fundamentos e possibilidades. Santos. 